\title{
A tribute to Seymour Steven Brody: in memoriam (November 29, 1927 to May 25, 2010)
}

\author{
Rhoda Elison Hirsch • Marvin Rich • Govindjee
}

Received: 16 November 2010/Accepted: 29 November 2010/Published online: 14 December 2010

(C) Springer Science+Business Media B.V. 2010

\begin{abstract}
We honor Steve Brody, a dear friend and a mentor on what would have been his 83rd birthday (November 29, 2010). Steve was a pioneer of chlorophyll structure and function, an outstanding biophysicist, an innovator, an artist and an adventurer, a true renaissance man. We present here first his first-of-a-kind contributions on the primary processes of photosynthesis at the University of Illinois at Urbana-Champaign, and then review his research on the interactions of chlorophyll monolayers and various photosynthetic electron donors and acceptors in artificial membrane systems at New York University. We highlight significant research contributions of interest to the reader and conclude with biographical notes.
\end{abstract}

This tribute to Seymour Steven Brody was written by Rhoda Elison Hirsch (REH) at the invitation of Govindjee, Founding Historical Corner Editor of Photosynthesis Research. Marvin Rich (MR) and Govindjee (GO) joined her to cover different aspects of Steve's research life. This tribute has been read and approved by members of Steve's family.

R. E. Hirsch $(\bowtie)$

Department of Medicine, Albert Einstein College of Medicine, Bronx, NY 10461, USA

e-mail: rhoda.hirsch@einstein.yu.edu

R. E. Hirsch

Department of Anatomy and Structural Biology, Albert Einstein College of Medicine, Bronx, NY 10461, USA

M. Rich

Morse Academic Program, New York University, New York, NY 10003, USA

Govindjee

Department of Plant Biology, University of Illinois

at Urbana-Champaign, Urbana, IL 61801, USA
Keywords Chlorophyll $\cdot$ Excitation energy transfer . Fluorescence - Lifetime of fluorescence - Monolayers . Photosynthesis · Fluorescence of heme-proteins . Molecular modeling

\section{Introduction}

A pioneer of chlorophyll structure and its role in photosynthesis has passed on. Seymour Steven Brody was a biophysicist, an innovator, a great teacher and mentor, as well as an artist, a pilot, a flight instructor, an adventurer (demonstrated by his transcontinental and trans-Atlantic flights in a small propeller plane), a first-degree black-belt and the higher second degree in karate, and a first-degree black-belt in Tae Kwando. Steve Brody was a true Renaissance man.

Steve Brody's research contributions were cutting edge. As part of his doctoral research under the mentorship of Eugene Rabinowich, Steve Brody designed an instrument to directly measure fluorescence lifetimes on the nanosecond scale. In a seminal research published in his doctoral thesis and in Science, he reported the first in vivo measurements of chlorophyll fluorescence lifetimes, and the time it takes to transfer energy from phycoerythrin to chlorophyll $a$ (Brody 1956; Brody and Rabinowitch 1957). This was soon followed by another first: the discovery of a new fluorescence band at $720 \mathrm{~nm}$, suggested to be from a "chlorophyll dimer" (Brody 1958). Steve continued to produce influential papers on chlorophyll and in collaboration with Marcia Brody for more than a decade (1959-1971). Novel approaches to define the long wavelength chlorophyll species were pursued by his postdoctoral fellows and doctoral students at New York University. We continue this tribute in the voice of Govindjee (GO, as 
Steve had called him) and his former students, Rhoda Elison Hirsch (REH) and Marvin Rich (MR).

\section{Contributions at Urbana, Illinois}

\section{GO}

Steve Brody was my senior when, in September 1956, I (GO) joined the world famous Emerson-Rabinowitch laboratory of photosynthesis, at the University of Illinois at Urbana-Champaign, located in the basement of the Natural History Building on Matthews Avenue in Urbana, Illinois. It was the Mecca of research on the "Light Reactions of Photosynthesis", whereas the University of California at Berkeley was the other equally renowned laboratory that focused on studying how $\mathrm{CO}_{2}$ makes sugars, where they had Melvin Calvin (who later received a Nobel Prize in Chemistry) and Andrew A. Benson (see Govindjee 2010, for a tribute). Urbana was where the Nobel laureate Otto Warburg had visited and where he and his former doctoral student Robert (Bob) Emerson could not agree on the minimum quantum (photon) requirement for the evolution of one molecule of oxygen in oxygenic photosynthesis. Emerson was proven right for his 8-12 photons over Warburg's 3-4 photons per $\mathrm{O}_{2}$ molecule. The laboratory at Urbana was buzzing with research activity all day and until late hours in the evening-sometimes to midnight. Emerson's laboratory used the most sophisticated manometers that measured pressure changes better than anybody else's in the world. Rabinowith's laboratory used state-of-the art absorption spectroscopy and fluorometry. (For descriptions of the two professors and the laboratory, see Bannister 1972; Brody 1995; Ghosh 2004; Govindjee 2004.) I was a beginning Ph.D. student of Emerson, whereas Steve Brody was already an established and accomplished student in Rabinowitch's group. There were others, but I was most impressed by Steve and his contributions. I shall just give a glimpse of some of Steve's discoveries made at the University of Illinois at Urbana-Champaign, some of which were already introduced above.

Steve was independent, ingenious, and very clever in getting things done. He had no fear of anything and no hesitation in delving into totally unfamiliar territory. Of course, everything was possible because Rabinowitch gave total independence to his students and postdocs, and Steve thrived on this freedom. Steve was the one to make the first direct measurement on the decay of chlorophyll fluorescence in vivo in the nanosecond time scale (see his own account in Brody 2002). No one had attempted such measurements in the field of photosynthesis. There was no equipment to even attempt to carry out such measurements. And Steve went right ahead and built the very first fluorescence lifetime instrument by sheer ingenuity, perseverance, and dedication. How did he do it? First of all, he designed and constructed a totally new instrument from scratch (Brody 1957); he exploited a new light source, a low pressure hydrogen lamp, with a flash duration of $2 \mathrm{~ns}$, which was being developed at the University of Illinois at Urbana-Champaign, by Malmberg (1957). Steve needed to use a special oscilloscope to achieve his goal; this was only available at the cyclotron lab at Urbana, Illinois, and that too only at nighttime. Steve did not hesitate to work from midnight until 8 in the morning every day during that period. There, he worked all night for almost 6 months. His adventurous spirit and his dedicated work paid off. Steve made the first direct measurements of the lifetime of fluorescence not only from chlorophyll in solution, but from chlorophyll $a$ in suspensions of the red alga Porphyridium, the green alga Chlorella, and the cyanobacterium Anacystis (Brody 1956, 1957; Brody and Rabinowitch 1957; Rabinowitch and Brody 1958). It is important to mention that independent of Brody's work at Urbana, Illinois, Alexander Terenin's famous laboratory at Leningrad University had also built an instrument, that had used a different method, the so-called phase method, and there, Dmitrievsky et al. (1957) also measured the chlorophyll $a$ fluorescence lifetime in vivo (see Borisov 2003). The lifetime of chlorophyll $a$ fluorescence was found to be in the range of 1 to $1.5 \mathrm{~ns}$ in photosynthetic systems, and this was almost 4-5 times shorter than for chlorophyll $a$ in solutions. Both research groups at Urbana and in Leningrad (St. Petersburg) concluded that the primary reaction of photosynthesis must be through the singlet-excited state of chlorophyll. Later my research group, and that of many others, have extended these lifetimes of fluorescence measurements; see an early review by Jursinic and Govindjee (1979).

Another first in the field of photosynthesis was then the measurement of the time (and thus, the rate) of excitation energy transfer from the orange-red pigment phycoerythrin to chlorophyll $a$ in the red alga Porphyridium cruentum (see Brody 1958, 1960; Rabinowitch and Brody 1958; Brody and Rabinowitch 1959). When excited by green light, absorbed by phycoerythrin, the measured time for energy transfer was $\sim 0.5 \mathrm{~ns}$. Much has progressed since then, but this measurement remains the first in the field. (For excitation energy transfer, see e.g., Clegg et al. 2010; Dutton 1997; Duysens 1952; French and Young 1952; Porter et al. 1978.)

As mentioned in the Introduction, Steve made still another discovery by using $77 \mathrm{~K}$ (liquid nitrogen temperature) spectroscopy after thinking about the obvious-that at low temperature biochemistry stops. Brody (1958) discovered a brand new emission band at $720 \mathrm{~nm}$ (F720). Steve had thought then that it was from a "chlorophyll dimer" (perhaps, the reaction center of Photosystem I, 
what is called P700); it is now known to originate from antenna chlorophyll a complex in Photosystem I. At $77 \mathrm{~K}$, another band at $696 \mathrm{~nm}$ (F696) was discovered independently in 1963 in several laboratories (including my (G) own and that of Steve Brody) (see reviews in: Govindjee et al. 1986; Govindjee 1995; Papageorgiou and Govindjee 2004). This $696 \mathrm{~nm}$ band is now assigned to originate in chlorophyll-protein complex (CP-47) in Photosystem II.

George Papageorgiou recently wrote to Govindjee about another interesting topic (photodynamic action of hypericin on cyanobacteria) on which he and Steve had worked together at Demokritos, Greece in the 1990s (see Papageorgiou et al. 1996; Brody et al. 1997). George remarked that during a short visit to his lab, Steve had impressed all his collaborators, and added "Steve was a great scientist, a great guy, a great human being of our times."

Govindjee ends this short snippet of Steve by mentioning that Steve was a very friendly person; he was the only one to call me "Go", first 2 letters of my name. When I spoke in Hindi on the telephone with my family and friends, he picked up one word "Accha"; it implies "OK" or "good". In good humor, he would often use it in conversation with me. After receiving his $\mathrm{PhD}$, and after only one semester of lessons from the School of Aviation, at the University of Illinois at Urbana, he obtained his private pilot license. He would rent one of the University airplanes and fly members of the Emerson-Rabinowitch Lab (as he would put it "those who would dare") to conferences. Jean Lavorel recently wrote, "I vividly remember that in February, 1957, we had all gone in an airplane piloted by Steve to Columbus (Ohio) to participate in a Biophysical Society meeting there. It was a fascinating experience". However, neither Rabinowitch, nor Emerson ever flew with him. I was too scared to fly with him although I did take a short ride once.

\section{Joint Research with Marcia Brody}

\section{$\mathrm{GO}$}

Marcia Brody was a former PhD student of Robert Emerson, and was also senior to me; she is currently Professor Emeritus of Hunter College, New York. Marcia is an accomplished scientist and had made major discoveries in the area of two-light effect and two photosystems in the red alga Porphyridium cruentum (see e.g., M. Brody and Emerson 1959a, b). Historically, it is important to point out that Marcia was a coauthor of an early abstract of a presentation by Robert Emerson (Emerson et al. 1956) that had some of the first hints on what led to the concepts of the two-light effect and two pigment systems of photosynthesis, based on the Emerson Enhancement Effect (Emerson et al. 1957; Rabinowitch and Govindjee 1960; R. Govindjee et al. 1960. (Both Govindjee and Rajni Govindjee were students of Emerson, but became students of Rabinowitch after Emerson died in a plane crash on Feb. 4, 1959.) Steve Brody collaborated with Marcia (see Biographical Portrait below) extensively since 1959 for a little more than 10 years. We mention only a few of their collaborative studies here. This collaboration included studies on dynamic changes in the efficiency of excitation energy transfer (Brody and Brody 1959; M. Brody and Brody 1961); and measurements on the optical properties and possible roles of aggregated forms of chlorophylls in vivo as well as in vitro (see e.g., Brody and Brody 1961). In particular, the idea that the reaction center of Photosystem I "P700" is an aggregated form of chlorophyll was emphasized by the two (Brody and Brody 1965). M. Brody and Brody (1962) provided an excellent review of the field of "Light Reactions in Photosynthesis"; this remains an important educational contribution. The two also initiated studies on fluorescence properties of Euglena during chlorophyll formation (Brody et al. 1965); and studied the effects of linolenic acid, among many things, on the two photosystems (Brody 1970; Brody et al. 1970). After almost a decade, the mechanism of linolenic acid inhibition on photosynthetic electron transport was rediscovered and subsequently, exploited to study partial reactions of the photosystems (see e.g., Golbeck et al. 1980; Warden and Csatorday 1987).

\section{Contributions at New York University}

From 1969 to 1992, Steve Brody's research efforts took a new perspective by exploring the interactions of chlorophyll monolayers and various photosynthetic electron donors and acceptors in artificial membrane systems, and also extended this approach to retinals and rhodopsin. Steve continued to design prototype biophysical instruments to spectrally characterize chlorophyll and proteins in monolayers.

\section{REH}

As a doctoral candidate at New York University (NYU), I was fortunate to have Steve as my professor and mentor (1974-1977). He was always available for discussion and dealt with all issues in an even, soft-toned manner. He created the curricula and taught two excellent upper-level graduate courses, "Photobiology" and "Instrumentation in Biology". Students enrolled in the later course scurried about his blacked-out laboratory, set atop the roof of NYU's Main Building, learning to use these instruments, helping to modify them, and acquiring data. My doctoral 
studies focused on direct spectral measurements of pure chlorophyll monolayers at a nitrogen-water interface in the presence and absence of redox compounds. Increasing surface tension gave rise to longer wavelength species. We concluded that in the monolayer, compression gives rise to various chlorophyll aggregated species (Hirsch and Brody 1979). The amount and specific chlorophyll species could be further induced by compression in the presence of reducing or oxidizing agents, with implications of chlorophyll orientation and complexation (Hirsch and Brody 1978, 1979, 1980).

After graduating in 1977, I began a Postdoctoral Fellowship in the Division of Hematology, Department of Medicine at the Albert Einstein College of Medicine. A few days a week, I returned to Steve's lab at NYU to collaborate, using the instrument that provided data for my doctoral dissertation. Steve collaborated with me, and my Einstein colleagues, on a project comparing the properties of monolayers of sickle cell hemoglobin ( $\mathrm{HbS}$ ) and normal hemoglobin at an air-water interface. Direct spectral measurements at this interface demonstrated that $\mathrm{HbS}$ unfolds to a significantly larger extent than $\mathrm{HbA}$ at the interface (Hirsch et al. 1980a). This conclusion provided one possible mechanism to explain established findings by others that $\mathrm{HbS}$ binds with greater affinity to the red blood cell membrane than does $\mathrm{HbA}$, with the implication of a conformational difference.

Steve was a resource. At the Einstein College of Medicine in 1977, with the aim of following resonance energy transfer in hemoglobin, I observed a weak hemoglobin fluorescence signal that I found to be detectable with a small cylindrical cuvette using right-angle optics in a standard fluorometer. I phoned Steve, asking how can one amplify a weak fluorescence signal? He provided me with critical information to try front-face fluorometry. His suggestion enabled me to break the dogma that heme-proteins do not emit significant fluorescence, establishing the use of front-face fluorescence to detect the fluorescence of hemoglobin and heme-proteins. By comparing the fluorescence of hemoglobin mutants, we concluded that the primary source of hemoglobin fluorescence is from $\beta 37$ Trp (located at the $\alpha 1 \beta 2$ interface, in the oxy to deoxy quaternary structural transition (Hirsch et al. 1980b; Hirsch and Nagel 1981). (For a review of hemoglobin fluorescence, see Hirsch 1994, 2000, 2003.)

Over the years, Steve and I remained in contact. Although Steve officially retired in 1997 from NYU, he already relocated, in 1995, to Denmark with Lis Stelzig, his wife, and their daughter Stephanie. In Denmark, Steve joined the Carlsberg Research Laboratories as a Visiting Professor (1997-2001). Victor Brody was born in 1996. I would see Steve, Lis and all of his children during their visits to New York, or when my husband, son and I were able to visit abroad with them. Steve, Lis, and his family became our close family friends. He was always there to listen and to share fun times, all in his easy, positive, and optimistic way. Thus, it is an honor and privilege to be asked to coordinate and co-author this tribute.

\section{MR}

I started working with Steve Brody in 1977 as a graduate student. Steve had just returned from Mauricio Montal's lab in Mexico, learning his method of creating lipid bilayer membranes that were formed without the use of solvent. It seemed clear that since I was interested in cell membranes that my work would revolve around solvent-free bilayers. I recall my first project was to build an apparatus that would create stable bilayer lipid membranes coupled with an electronic apparatus to measure the electrical properties of the bilayer member. I was fortunate to have James (Jim) Woodley to assist me with this project that included devising a sophisticated voltage clamp apparatus necessary to measure highly sensitive electrical properties of bilayer systems. In addition, Jim Woodley assisted me in building several additional solvent-free and solvent containing bilayer systems that were used for many years of research. (See Fig. 1 for a photo of Steve with Jim Woodley.) One of the first projects Steve and I worked on was to study the role of chlorophyll in mediating electron transfer in the solvent-free bilayer systems. A comparison was made to the standard solvent containing bilayer system. We found that the photocurrent/area was about an order of magnitude higher in bilayers formed with the solvent-free method. From quantum yield calculations, it appeared that the higher photocurrent/area obtained with the Montal-Mueller membranes could not be explained solely due to the greater concentration of pigment molecules in the solvent-free system, thus suggesting a possible role of chlorophyll-chlorophyll

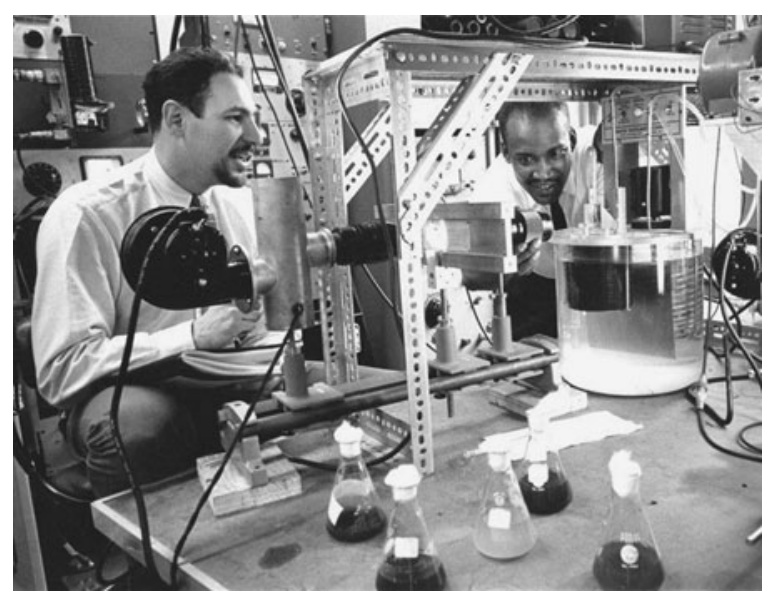

Fig. 1 Steve Brody (left) and Jim Woodley (right) at International Business Machines (IBM) Watson Laboratories in the 1960s 
interactions (Rich and Brody 1981). We went on to study the effects that various carotenoids played on increasing electron transfer in the solvent-free bilayers and discovered that the dihydroxy carotenoids were significantly more efficient in electron transfer than beta carotene (Rich and Brody 1982). In the early 1990s, we became interested in the role of carotenoids as an antioxidant and reported that the dihydroxycarotenoids were significantly more protective against reactive oxygen species than beta carotene (Rich et al. 1992).

Steve often spent his summers working in labs overseas. Several of these experiences developed into interesting projects during the school year. On one visit Steve became interested in the effects of pressure on the spectra of phycobiliproteins (Brody and Stelzig 1983). This led to a lab effort to study the effects of elevated pressure on the permeability of adriamycin between neoplastic and normal lung cells (Brody et al. 1987).

On another trip Steve visited the laboratory of Jean-Jacques Legendre at the Laboratoire d'Electrochimie et de Chimie Analytique in Paris. At the time, Jean-Jacques was using computational modeling to study small molecule systems. Jean-Jacques introduced Steve to several molecular modeling software packages. For both Steve and myself, this opened a door to a field of research that could virtually be done anywhere if there was access to a computer terminal. Steve directed his interest to predicting protein structure using homology software at the Department of Physiology, Carlsberg Research Center in Copenhagen. The predicted structure and fold recognition for the ferrochelatase protein (Hanson et al. 1997) and for the glutamyl tRNA protein (Brody et al. 1999) are deposited in the Brookhaven Database as ID1FJI and ID1b61, respectively. Since I was still teaching in the New York City school system, I decided to develop several activities that would introduce the world of Molecular Modeling to K-12 students. The project was developed at the NYU Scientific Visualization Center at the same time the Internet was just emerging and allowed for rapid dissemination of the project to the K-12 community. The site called MathMol: Mathematics and Molecules (http://www.nyu.edu/pages/mathmol/) continues to be actively used by many High School and College students. The aim of the site is to provide students and teachers basic concepts in mathematics and their connection to the world of molecules.

Steve was not only my (MR) mentor but also a great personal friend. I often traveled to Europe to visit him and I remain a friend of his family to this day.

\section{Biographical portrait}

Seymour Steven Brody was born in the Bronx in New York City. He wrote that he "always wanted to be a pilot, so for high school I elected to go to an 'aviation school', Haaren High School in Manhattan where I excelled in mathematics and science." He was a maverick, even as a youth. His autobiographical notes state:

"Ran off to join Navy (at age 15 or 16). My parents found out I joined the Navy, from another friend of mine. I had a cousin who was a captain in the Navy... (who) located me in the Navy training base in upstate New York. After several months they gave me an honorable discharge, as an underage minor [US Navy, May 23, 1944 until June 21, 1944 (20 days)]". Steve was then drafted into the US Army (Feb. 25, 1946 to August 29, 1946); and re-enlisted on August 30, 1946 and served until August 16, 1947. "After the Army, I went back to night school (Evander Childs) to complete my high school education, so I could apply to college. I did perfect in algebra and geometry."

Steve took the NYC fireman's test and passed, but started college since he was not called up for training. According to Steve's autobiographical notes, he might not have started school at all had he started training as a fireman! Nevertheless, Steve went on to graduate in 1950 from City College of New York (New York City) with a B.S. in Physics. He then enrolled at New York University as a night student for his M.S. in Physics. From 1950 to 1951, he worked full time during the day as an electronic scientist at the NY Naval Shipyard, in Brooklyn, NY testing cathode ray tubes to determine if they met Navy specifications. From 1952 to 1953, he held another job as a physicist for the US Army Signal Corps at Ft. Monmouth, NJ because it was closer to Rutgers University where Marcia Brody (his first wife) held a teaching fellowship in biology to study for her Masters degree. Commuting to his job at Ft. Monmouth during the day and driving to NYU at night, he completed his M.S. in Physics at New York University in 1953. At the University of Illinois by 1953, both Marcia and Steve received fellowships for doctoral studies with Steve in the laboratory of Eugene Rabinowitch and Marcia Brody in the laboratory of Robert Emerson. In 1956, Steve received his Ph.D. in PhysicoChemical Biology (PCB, as it was called; later this program was renamed as Biophysics) from the University of Illinois at Urbana-Champaign. In 1960, he took a position at the U.S. Air Force Research Center, and in 1961 he was appointed Manager of Biophysics at the prestigious Watson Laboratories of IBM (International Business Machines) (Fig. 2). In 1965, he was awarded the National Institutes of Health Career Development Award (1965-1970) with an appointment to the faculty in the Department of Biology at New York University. Steve spent vacations and sabbaticals as a Visiting Professor in research laboratories all over the world, including the laboratories of Helmut Metzner (Germany), Sir George Porter (London), Louis N.M. Duysens (Netherlands) and others in India, Mexico City, Greece, Japan and Hawaii (USA). 


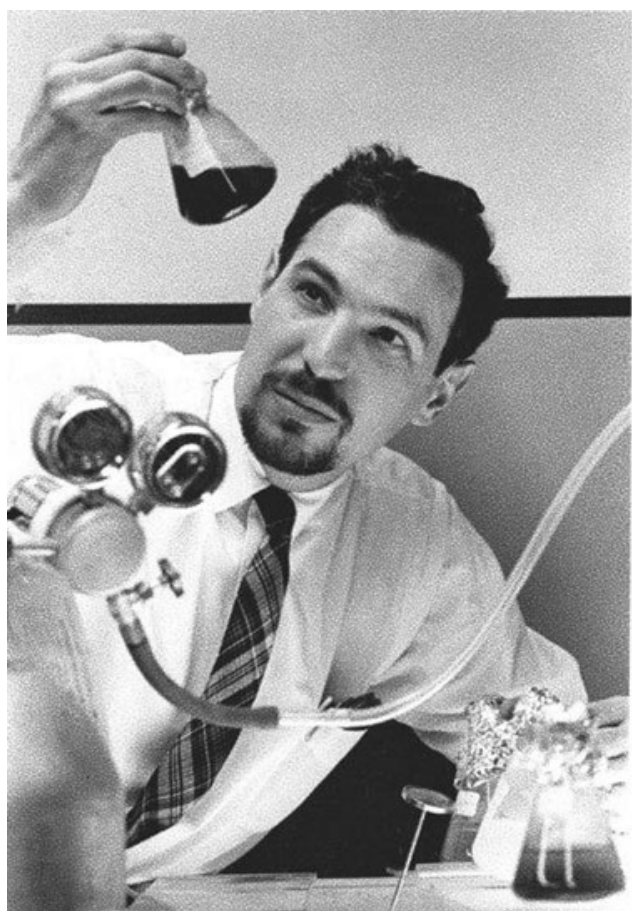

Fig. 2 Steve Brody looking at a suspension of an experimental sample at IBM in the 1960 s

For a complete list of almost 94 publications by Seymour Steven Brody, search Brody SS in PubMed or other literature data bases. However, to give the readers a breadth of Steve's research and his association with other scientists, we provide here a list of selected references, arranged chronologically (See Appendix).

\section{Epilogue}

On his 80th birthday, Steve Brody looked not a day older than 65 years and had the energy and vitality of a much younger man (See Figs. 3 and 4 for two of his portraits). During his nearly 2 year illness, he would say, "You cannot stop moving". Steve continued to travel and live life. Only in his last few weeks did one realize that his illness was seriously compromising when he no longer worked out in the gym. Realizing he was losing a battle, Steve wrote the following words to his friends and family:

"So I just want to say, I have had a fantastic wonderful, fun filled life with lots of adventures and no regrets. I thank you all for being part of it. It has been wonderful to know you."

On May 25, 2010, Steve Brody passed away at the age of 82 . He is survived by his wife Lisbeth Stelzig and their children Stephanie and Victor; his first wife, Marcia Brody and their children: Stuart Brody, Benjamin (Ben) Brody,

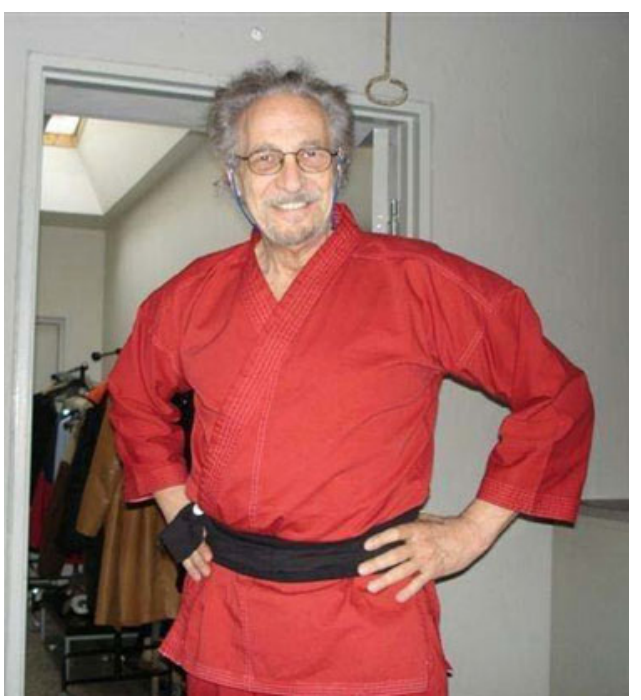

Fig. 3 Steve Brody recruited to play a role as a Karate Master in a Danish film, 2007

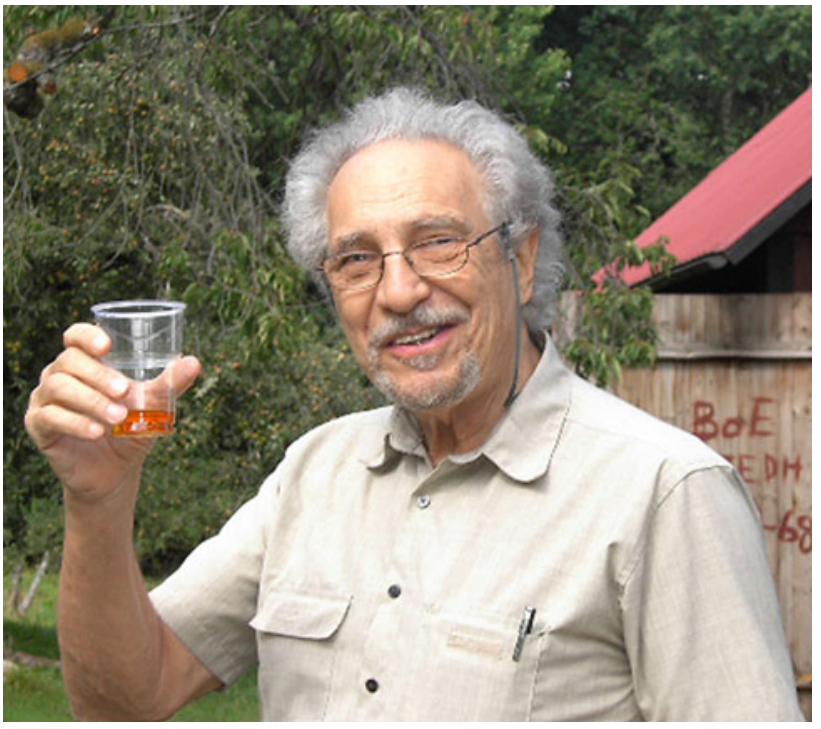

Fig. 4 Steve Brody at his best, celebrating his life, his family, and friends, 2008

Erica Brody and son-in-law, Richard Haw; and his niece, Florence Fisher, her husband, Stan Fisher and their family. During the last days of his life, Steve was looking forward to the November 2010 arrival of his first grandchild (parents: Erica Brody and Richard Haw).

Acknowledgments We are very grateful to Lis Stelzig for providing us with Steve's curriculum vitae, biographical details, and photos. We appreciate her kind support in finishing this tribute. The authors also thank Benjamin Brody, Erica Brody, Stephanie Brody, and Victor Brody for their encouragement and input. We thank Jean Lavorel, George Papageorgiou, Norio Murata and Prasanna Mohanty for their wonderful comments on Steve and on his research in the area of photosynthesis. We are also grateful to Jean-Jacques Legendre for 
his cordial personal remarks on their friendship and association. The authors appreciate the support of Marcia Brody and Suse Broyde for this Tribute. Govindjee is thankful to the offices of Plant Biology and of Information Technology (Life Sciences) at the University of Illinois at Urbana-Champaign. Rhoda Elison Hirsch acknowledges with appreciation the American Heart Association for their support in part (Grant-in-Aid No. 0755906T).

\section{Appendix}

$1960 \mathrm{~s}$

Brody SS and Broyde SB (1963) A low temperature emission band from dilute solution of pure chlorophyll a. Nature 199: 1097-1098

Brody SS, Ziegelmair CA, Samuels A and Brody M (1966) Effect of method of preparation on the states of chlorophyll in Euglena chloroplast fragments as determined by fluorescence spectroscopy. Plant Physiol 41: 1709-1714

Broyde SB and Brody SS (1967) Emission spectra of chlorophyll $a$ in polar and nonpolar solvents. J Chem Phys 46: $3334-3340$

Nathanson B, Brody M, Brody SS and Broyde SB (1967) The mechanism of the flavin sensitized photodestruction of indoleacetic acid. Photochem Photobiol 6: 177-187

Brody M, Broyde SB, Yeh CC and Brody SS (1968) Chlorophyll-sensitized oxidation-reduction reactions of hemin in pyridine. Biochem 7: 3007-3015

Aghion J, Broyde SB and Brody SS (1969) Surface reactions of chlorophyll $a$ monolayers at a water-air interface. Photochemistry and complex formation. Biochem 8: 3120-3125

Balny C, Brody SS and Hoa GHB (1969) Absorption and fluorescence spectra of chlorophyll $a$ in polar solvents as a function of temperature. Photochem Photobiol 9: $445-454$

$1970 \mathrm{~s}$

Brockman RE and Brody SS (1971) Photoreactions and complex formation of retina monolayers at a water-air interface. Z Naturforschg 26b: 119-125

Jacobs R and Brody SS (1971) Restorative effect of warming on the fluorescence intensity and fluorescence induction of photosynthetic material at $77 \mathrm{~K}$. Biochim Biophys Acta 267: 341-347

Reinach P and Brody SS (1972) Oxidative titration of monomolecular films of cytochrome c-II and of bacteriochlorophyll. Biochem 11: 92-96

Reinach P, Aubrey BB and Brody SS (1973) Monomolecular films of bacteriochlorophyll and derivatives at an air-water interface: Surface and spectral properties. Biochim Biophys Acta 314: 360-371

Karan J and Brody SS (1974) Chlorophyll $a$ and cytochrome $\mathrm{c}$ at a heptane-water interface. Z Naturforschg 29c: 506-509

Yckowski N and Brody SS (1974) Interactions of monomolecular films of retinal at alkaline $\mathrm{pH}$. Z Naturforschg 29c: $327-335$

Chin P and Brody SS (1975) Surface properties of monomolecular films of oxidized and reduced cytochrome $c$ and $f$. Biochem 14: 1190-1193

Puppala N and Brody SS (1975) Interactions between retinal and phospholipids in monomolecular films at acid pH. Z Naturforschg 30c: 478-483

Brody SS and Owens NF (1976) Photosynthetic electron carriers at a heptane-water interface. Z Naturforschg 31c: 569-574

Brody SS and Singhal GS (1979) Spectral properties of chloroplast membranes as a function of physiological temperatures. Biochem Biophys Res Comm 89: 542-546

1980s

Vivino A, Berns DS and Brody SS (1980) Light and $\mathrm{pH}$ induced changes in the surface pressure-area isotherms of bacteriorhodopsin. Photochem Photobiol 31: 363-366

Brody SS and Gregory R (1981) Effect of hydrogen ion concentration on the absorption spectrum and picosecond fluorescence of chloroplasts. Z Naturforschg 36c: 638-644

Brody SS, Barber J, Treadwell C and Beddard G (1981) Effects of linolenic acid on the spectral properties and picosecond fluorescence of pea chloroplasts. Z Naturforschg 36c: 1021-1024

Brody SS, Porter G, Treadwell CJ and Barber J (1981) Picosecond energy transfer in Anacystis nidulans. Photobiochem Photobiophys 2: 11-14

Brody SS, Treadwell CJ and Barber J (1981) Picosecond energy transfer in Porphyridium cruentum and Anacystis nidulans. Biophys J 34: 439-449

Brody SS and Duysens LNM (1984)Temperatureinduced changes in pigment-protein interaction as reflected by changes in the absorption spectrum of Rhodopseudomonas sphaeroides. Photobiochem Photobiophys 7: 299-309

Brody SS and Hereman K (1984) Pressure induced shifts in spectral properties of pigment-protein complexes and photosynthetic organisms. Z Naturforschg 39: 1104-1107

Brody SS and Feliccia VL (1986) A spectrofluorometer to measure difference in fluorescence spectra: A simple method for improving sensitivity. J Biochem Biophys Methods 12: 319-323 
$1990 \mathrm{~s}$

Lemoine Y, Zabulon G, Brody SS (1992) Pigment distribution in photosystem II. In: Murata N (ed) Research in photosynthesis, vol 1. Kluwer, Dordrecht, pp 331-334

Brody SS, Andersen JS, Kannangara CG, Meldgaard M, Roepstorff P and vonWettstein D (1995) Characterization of the different spectral forms of glutamate 1-semialdehyde aminotransferase by mass spectrometry. Biochemistry 34 : 15918-15924

\section{References}

Bannister TT (1972) The careers and contributions of Eugene Rabinowitch. Biophys J 12:707-718

Borisov A (2003) The beginnings of research on biophysics of photosynthesis and initial contributions made by Russian scientists to its development. Photosynth Res 76:413-426

Brody M, Brody SS (1961) Induced changes in photosynthetic efficiency of pigments in Porphyridium cruentum, II. Arch Biochem Biophys 96:354-359

Brody M, Brody SS (1962) Photosynthesis-light reactions. In: Lewin R (ed) The physiology and biochemistry of the algae. Academic Press, New York, pp 3-23

Brody M, Emerson R (1959a) The effect of wavelength and intensity of light on the proportion of pigments in Porphyridium cruentum. Am J Bot 46:433-440

Brody M, Emerson R (1959b) The quantum yield of photosynthesis in Porphyridium cruentum, and the role of chlorophyll $a$ in the photosynthesis of red algae. J Gen Physiol 43:251-264

Brody SS (1956) Fluorescence lifetimes of photosynthetic pigments in vivo and in vitro. $\mathrm{PhD}$ thesis, University of Illinois at Urbana-Champaign (Dissertation Abstracts 17: 484-485, 1957)

Brody SS (1957) Instrument to measure fluorescence lifetimes in the millimicrosecond region. Rev Sci Instr 28:1021-1026

Brody SS (1958) A new excited state of chlorophyll. Science 128:838-839

Brody SS (1960) Delay in intermolecular and intramolecular energy transfer and life times of photosynthetic pigments. Z Elektrochem 64:187-203

Brody S (1970) The effects of linolenic acid and extracts of Ricinus leaf on system I and system II. Z Naturforschung 25:855-859

Brody SS (1995) We remember Eugene (Rabinowitch and his laboratory during the fiflies). Photosynth Res 43:67-74

Brody SS (2002) Fluorescence lifetime, yield, energy transfer and spectrum in photosynthesis, 1950-1960. Photosynth Res 73:127-132

Brody SS, Brody M (1959) Induced changes in the efficiency of energy transfer in Porphyridium cruentum I. Arch Biochem Biophys 82:161-178

Brody SS, Brody M (1961) Spectral characteristics of aggregated chlorophyll and its possible role in photosynthesis. Nature (London) 189:547-549

Brody SS, Brody M (1965) An experiment showing that P700 can be an aggregated form of chlorophyll $a$. Arch Biochem Biophys 110:583-585

Brody SS, Rabinowitch E (1957) Excitation lifetimes of photosynthetic pigments in vivo and in vitro. Science 125:555-557

Brody SS, Rabinowitch E (1959) Energy transfer and photosynthesis. First National Biophysics Conference, Yale University Press, pp 110-121
Brody SS, Stelzig L (1983) Effect of pressure on the absorption spectra of phycobiliprotein and Porphyridium cruentum. Z Naturforsch 38c:458-460

Brody SS, Brody M, Levine J (1965) Fluorescence changes during chlorophyll formation in Euglena gracilis (and other organisms) and an estimate of lamellar area as a function of age. J Protozool 12:465-476

Brody SS, Brody M, Döring G (1970) Effects of linolenic acid on system II and system I-associated light induced changes in absorption of chloroplasts. Zeit f Naturforschgung 25b:367-372

Brody SS, Stelzig L, Ferraro G, Rich M (1987) Use of elevated pressure to promote the difference in permeability of adriamycin (C) and hematoporphyrin between neoplastic and normal lung cells. Cancer Biochem Biophys 9:133-138

Brody SS, Papageorgiou G, Alygizaki-Zorba A (1997) Photodynamic action of hypericin on cyanobacteria Synechocystis and Synechococcus (Anacystis nidulans). Z Naturforsch 52c:165-168

Brody SS, Gough SP, Kannangara CG (1999) Predicted structure and fold recognition for the glutamyl tRNA reductase family of proteins. Proteins 37:485-493

Clegg RM, Sener M, Govindjee (2010) From Förster Resonance Energy Transfer (FRET) to Coherent Resonance Energy Transfer (CRET) and Back-Awheen o' mickles mak's a muckle. In: Alfano RR (ed) Optical biopsy VII, Proceedings of SPIE, Vol. 7561 (SPIE, Bellingham, WA, 2010), paper number: 7561-12; article CID number: $75610 \mathrm{C}, 21 \mathrm{pp}$

Dmitrievsky OD, Ermolaev VL, Terenin AN (1957) The fluorescence lifetime of chlorophyll $a$ in Chlorella cells. Proc USSR Acad Sci 114:75-78

Dutton H (1997) Carotenoid-sensitized photosynthesis: quantum efficiency, fluorescence and energy transfer. Photosynth Res $52: 175-185$

Duysens LNM (1952) Transfer of excitation energy in photosynthesis. Doctoral Thesis, State University, Utrecht, The Netherlands

Emerson R, Chalmers R, Cederstrand C, Brody M (1956) Effect of temperature on the long-wave limit of photosynthesis. Science 123:673

Emerson R, Chalmers RV, Cederstrand CN (1957) Some factors influencing the longwave limit of photosynthesis. Proc Natl Acad Sci USA 43:133-143

French S, Young VMK (1952) The fluorescence spectra of red algae and the transfer of energy from phycoerythrin to phycocyanin and chlorophyll. J Gen Physiol 35:873-890

Ghosh AK (2004) Passage of a young Indian physical chemist through the world of photosynthesis research at Urbana, Illinois, in the 1960s: a personal essay. Photosynth Res 80:427-437

Golbeck JH, Martin IF, Fowler CF (1980) Mechanism of linolenic acid-induced inhibition of photosynthetic electron transport. Plant Physiol 65:707-713

Govindjee (1995) Sixty-three years since Kautsky: chlorophyll $a$ fluorescence. Aust J Plant Physiol 22:131-160

Govindjee (2004) Robert Emerson, and Eugene Rabinowitch: understanding photosynthesis. In: Hoddeson L (ed) No Boundaries: University of Illinois Vignettes, Chap. 12. University of Illinois Press, Urbana and Chicago, pp. 181-194. ISBN: 0-252-0703-0 (paperback)

Govindjee (2010) Celebrating Andrew Alm Benson's 93rd birthday. Photosynth Res. doi: 10.1007/s11120-010-9591-3

Govindjee R, Thomas JB, Rabinowitch E (1960) The second Emerson effect in the Hill reaction of Chlorella cells with quinone as oxidant. Science 132:421

Govindjee, Amesz J, Fork DC (eds) (1986) Light emission by plants and bacteria. Academic Press, Orlando, Florida

Hanson M, Gough SP, Brody SS (1997) Structure prediction and fold recognition for the ferrochelatase family of proteins. Proteins 27:517-522 
Hirsch RE (1994) Front-face fluorescence spectroscopy of hemoglobins. Methods Enzymol 232:231-246

Hirsch RE (2000) Heme protein fluorescence. In: Lakowicz JR (ed) Topics in fluorescence spectroscopy, Chap 10, vol 6: protein fluorescence. Kluwer Academic/Plenum Publishers, New York, pp. 221-255

Hirsch RE (2003) Hemoglobin fluorescence. In: Nagel RL (ed) Methods in hemoglobin disorders. Series in molecular medicine. Humana Press, New Jersey, pp 133-154

Hirsch RE, Brody SS (1978) Spectral properties of chlorophyll$a$ monolayers in the presence of an exogenous electron donor and acceptor. Eur J Biochem 89:281-286

Hirsch RE, Brody SS (1979) Spectral properties of chlorophyll $a$ monolayers: monolayers of chlorophyll $a$ and pheophytin at a gas-water interface. Photochem Photobiol 29:589-596

Hirsch RE, Brody SS (1980) Absorption spectra of mixed monomolecular films of chlorophyll and photosynthetic electron carriers at a gas-water interface. Arch Biochem Biophys 199:506-514

Hirsch RE, Nagel RL (1981) Conformational studies of hemoglobins using intrinsic fluorescence measurements. J Biol Chem 256:1080-1083

Hirsch RE, Elbaum D, Brody SS, Nagel RL (1980a) Hemoglobin-A and hemoglobin-S films at an air-water interface: absorption spectra studies. J Colloid Interface Sci 78:212-216

Hirsch RE, Zukin RS, Nagel RL (1980b) Intrinsic fluorescence emission of intact oxy hemoglobins. Biochem Biophys Res Commun 93:432-439

Jursinic P, Govindjee (1979) Photosynthesis and fast changes in light emission by green plants. Photochem Photobiol Rev 4:125-205
Malmberg JH (1957) Millimicrosecond duration light source. Rev Sci Instr 28:1027-1030

Papageorgiou GC, Govindjee (eds) (2004) Chlorophyll $a$ fluorecence: a signature of photosynthesis. Springer, Dordrecht (reprinted in 2010 in softcover)

Papageorgiou GC, Alygizaki-Zorba A, Loukas S, Brody SS (1996) Photodynamic effect of hypericin on photosynthetic electron transport and fluorescence of Anacystis nidulans (Synechococcus 6301). Photosynth Res 48:221-226

Porter G, Tredwell CJ, Searle GFW, Barber J (1978) Picosecond time-resolved energy transfer in Porphyridium cruentum. Biochim Biophys Acta 501:232-245

Rabinowitch E, Brody SS (1958) Transferts d'energie et photosynthése. J Chim Phys 55:925-933

Rabinowitch E, Govindjee (1960) Two forms of chlorophyll $a$ in vivo with distinct photochemical functions. Science 132:355-356

Rich M, Brody SS (1981) A quantitative comparison of chlorophyll bilayers formed with and without solvent. Photochem Photobiol 33:271-274

Rich M, Brody SS (1982) Role of various carotenoids in mediating electron transfer sensitized by chlorophyll and pheophytin. FEBS Lett 143:45-48

Rich M, DeStrulle R, Ferrara G, Brody SS (1992) Dihydroxycarotenoids inhibit phtotoxicity in Paramecium caudatum. Photochem Photobio 26:413-418

Warden JT, Csatorday K (1987) On the mechanism of linolenic acid inhibition in Photosystem II. Biochim Biophys Acta 890: $215-223$ 